\title{
O Impacto da Desvinculação de Receitas da União nas Políticas Públicas de Saúde
}

\author{
Antonio Bazilio Floriani Neto* \\ Danielle Anne Pamplona**
}

1 Introdução. 2 A seguridade social brasileira. 3 Políticas públicas de saúde - o SUS. 4 As limitações orçamentárias e o financiamento da saúde. 5 A desvinculação de Receitas da União. 6 Considerações finais. Referências.

\section{RESUMO}

A Constituição de 1988 implementou o modelo de Seguridade Social em solo pátrio, composto pela Previdência, pela Assistência e pela Saúde. Trata-se de direitos sociais, de segunda dimensão, que necessitam de um agir do aparelho estatal. Para os fins do presente artigo, o corte metodológico é realizado na Saúde e, em especial, na forma com que a ordem estabelecida propôs para efetivá-la: mediante políticas públicas. Para atingir essa finalidade, é indispensável a existência de recursos. E o orçamento da Seguridade Social é afetado, diretamente, por um instituto denominado Desvinculação de Receitas da União (DRU), responsável por atribuir finalidade diversa ao montante arrecadado a título de contribuições sociais. Assim, resta controversa a premissa de ausência de recursos financeiros para o Estado fornecer a devida proteção ao indivíduo nessa seara, sendo o objetivo deste artigo aprofundar o conhecimento do tema. Para atingir esse desiderato, o trabalho abordou inicialmente a seguridade social brasileira, com enfoque no SUS, para então examinar as políticas públicas de saúde, o seu financiamento e, por fim, a DRU.

Palavras-chave: Seguridade Social. Desvinculação de Receitas da União. Políticas Públicas. Saúde.

\section{INTRODUÇÃO}

Não é recente o debate envolvendo a efetividade das políticas públicas que visam a garantir direitos fundamentais estabelecidos pela Constituição de 1988; e, no caso específico da saúde, a situação é ainda mais problemática.

* Doutorando e mestre (2013) em Direito Econômico pela PUCPR. Possui graduação em Direito (2011) e especialização em Direito Previdenciário (2013) pela PUCPR. Editor da Revista de Direito Empresarial (RDEMP). Advogado, professor da Faculdade Curitibana (FAC) e de cursos de pós graduação lato sensu. E-mail: <antonio@rochaefloriani.com.br>.

** Professora Titular do Programa de Pós-Graduação da Pontifícia Universidade Católica do Paraná. Research Scholar no Washington College of Law na American University, Washington, DC (2015-2016); Doutora pela Universidade Federal de Santa Catarina; Coordenadora da Clínica de Direitos Humanos da PUCPR. E-mail: <dapamplona@pamplonaebraz.com.br>. 
A Constituição de 1988 é conhecida por avançar no tema da saúde com a implementação de um paradigma há muito exigido pela sociedade e expresso na VIII Conferência Nacional de Saúde, realizada em 1986. Já àquela época, a demanda era pela implementação de um Sistema Unificado e Descentralizado de Saúde, que permitiu que os investimentos fossem aplicados majoritariamente ao setor público. Este foi o embrião do que seria adotado pelo texto constitucional, o Serviço Único de Saúde (SUS), em que as ações e os serviços de saúde são fornecidas de forma igualitária, gratuita e universal, implementadas pelo Sistema que é conhecido por ter uma estrutura precária e por não contar com profissionais suficientes para atender à demanda. Por causa disso, fala-se que o SUS é moroso e ineficiente.

Nesse contexto, é recorrente a ideia de que os recursos do Estado são escassos para atender às necessidades da população. Tem-se, aqui, a relação de políticas públicas e orçamento, considerada por Torres (2005) como dialética: o orçamento pode prever e autorizar despesas para implementação de políticas públicas, ocorre que estas dependem de aspectos orçamentários.

Diante disso, os direitos sociais reclamam para que sejam efetivados de recursos. Assim, cria-se a imagem de que o problema elementar das políticas públicas de saúde no Brasil é econômico. Não por acaso, o Poder Judiciário é provocado, com frequência, para manifestarse sobre o elastecimento de direitos inerentes à saúde.

A Saúde é parte integrante da Seguridade Social, sistema destinado a cobrir os riscos sociais, do qual fazem parte, ainda, a Previdência e a Assistência. Para poder fornecer essa proteção, pensou o constituinte em implementar uma fonte de custeio. Em solo pátrio, a Seguridade Social é financiada pelas contribuições sociais, as quais foram instituídas para custear essa finalidade específica. Consequentemente, o destino da arrecadação é considerado elemento essencial para as contribuições.

Ocorre que a viabilidade desse sistema vem sendo afetada pela desvinculação de parcela do arrecadado, por meio da Desvinculação de Receitas da União (DRU). A DRU é um instrumento legal de retirada de recursos da União, cujo objetivo é conferir maior flexibilidade orçamentária para alocação de receitas.

Tecidas essas considerações, o presente artigo busca desmistificar o argumento de escassez econômica nas políticas públicas de saúde. Enquanto perdurar a DRU, não haverá legitimidade para embasar proposta de elevação da carga tributária, com vistas a garantir eficiência a esses direitos fundamentais.

Para tanto, o artigo foi dividido em itens. No primeiro, examinar-se-á a saúde como parte da seguridade social. Em seguida, far-se-á um breve histórico do SUS, para então chegar ao conceito de políticas públicas. Tendo esses conceitos em mente, o artigo passa a abordar, especificamente, a forma de funcionamento e as restrições orçamentárias, para, ao final, chegar à desvinculação de receitas da união e ao impacto ocasionado na seguridade social. 


\section{A SEGURIDADE SOCIAL BRASILEIRA}

Ao longo do tempo e do espaço, a conjuntura social se forma com suas próprias características e peculiaridades. Pensadores como Comte, Tocqueville, Durkheim, Weber e Marx tiveram interesse no estudo de sociedade e em questões tais como se existiram alguma sociedade mais eficaz em promover desenvolvimento e bem-estar social do que outras (HALL; LAMONT, 2009).

Modernamente, as ciências sociais mudaram o seu modo de pesquisa, haja vista a dificuldade de mensuração de um fenômeno complexo, resultante da ação de vários indivíduos, por meio da elaboração de premissas gerais, abstratas. Em outros termos, a teia de relações sociais responsável por conectar pessoas exige uma postura empírica, bem como a análise de outras dimensões, proporcionadas pelas mais variadas ciências.

As sociedades podem ser definidas como padrões de relações sociais estruturadas por práticas institucionais e repertórios culturais (HALL; LAMONT, 2009). As instituições e as estruturas culturais têm impacto na promoção do bem-estar social, que será diferente de acordo com o nível de desenvolvimento e sucesso apresentado por diferentes sociedades. Não há um único caminho para o sucesso, sendo a interação entre instituições e cultura local o que difere uma das outras. Desse modo, é inócuo sustentar a existência de um pacote de ações aplicável indistintamente a qualquer país.

Logo, apesar de governos buscarem maneiras de aprimorar o sistema de saúde para seus cidadãos, resta controversa a melhor maneira de atingir esse objetivo (HALL; TAYLOR, 2009), eis que cada país tem suas próprias características e instituições, formais e informais.

Ademais, a saúde comporta concepções distintas, definidas de acordo com o paradigma de Estado vigente. Sob uma perspectiva liberal, de intervenção mínima do estado na ordem econômica, ganha espaço a concepção privatista; já sob o enfoque do Estado Social, a sanitarista. Ambas as concepções visualizam o indivíduo como um cliente do Estado e, assim, do sistema de saúde, não sendo a forma com que o direito é tutelado na Constituição de 1988 (DORES, 2013).

A ordem constitucional estabelecida em 1988 utiliza o conceito de Estado de Direito, que visa a "superar o déficit de cidadania evidenciado nos paradigmas do Estado Liberal e do Estado Social e passar a conceber esse direito fundamental como um processo, uma participação efetiva." (DORES, 2013, p. 78). A Constituição de 1988 é considerada dirigente, objetiva a mudança social por meio de ações do Estado e de toda a sociedade. Nesse contexto, a saúde foi protegida como um bem de relevância pública, cabendo a todos o seu cuidado (DIAS et al., 2016).

A saúde é consagrada como direito social, conforme consta no artigo $6^{\circ} .{ }^{1}$ Por não estar listada no rol dos direitos fundamentais (art. $5^{\circ}$ ), pode surgir o questionamento acerca da sua fundamentabilidade. Eurípedes Gomes Faim Filho esclarece que se trata de um direito fundamental, especialmente pelo fato de que, sem saúde, não é possível garantir o direito à vida: 
"uma vida sem saúde é uma vida violada e a morte se pode dizer que é a total ausência de saúde, razão pela qual negar esse direito é negar o direito à vida.” (FAIM FILHO, 2011, p. 1013).

A saúde é também abordada no título VIII do texto constitucional, responsável por abordar a ordem social. No artigo 194, o texto implementa um modelo protetivo em nosso país, responsável por assegurar os direitos relativos à saúde, à previdência e à assistência. ${ }^{2}$ Trata-se da Seguridade Social, cujos princípios estão listados no parágrafo único do mencionado artigo, dentre os quais ressaltam-se a universalidade de cobertura e atendimento, uniformidade e equivalência dos benefícios e serviços às populações urbanas e rurais, seletividade, irredutibilidade do valor dos benefícios, dentre outros. Esse sistema de proteção social, portanto, emerge da vulnerabilidade dos indivíduos diante dos riscos, os quais exigem a elaboração e implementação de políticas públicas.

Por meio desses dispositivos, observa-se que a Constituição busca conferir proteção social ao cidadão. Essa proteção oferece cobertura aos riscos "[...] suscetíveis de gerar uma degradação da situação dos indivíduos" (SAVARIS, 2016, p. 43), diferenciando-se da civil, atrelada às liberdades fundamentais, assegurando aos indivíduos bens em um Estado de Direito.

Nas palavras de Nelson Rodrigues dos Santos, "proteção social é a garantia pública do acesso universal a bens e serviços essenciais à dignidade humana, não garantidos pelo mercado" (SANTOS, 2013, p. 5), citando como exemplos a saúde, a educação, a segurança, a habitação, a cultura e a previdência.

A Constituição de 1988, portanto, não se limitou a estabelecer limites do poder público ou das liberdades políticas, foi além: abordou os direitos fundamentais e os sociais, representando "[...] uma mudança de paradigma no fenômeno do direito, a modificar a postura abstencionista do Estado para o enfoque prestacional, característico das obrigações de fazer que surgem com os direitos sociais." (BUCCI, 2006, p. 2-3).

Tecidas essas considerações, passa-se a examinar, brevemente, cada uma das bases da Seguridade Social: a Previdência, a Assistência e a Saúde.

A Previdência, em síntese, destina-se à cobertura dos riscos que podem comprometer a capacidade dos indivíduos de, por conta própria, prover a sua independência, tais como a velhice, a morte, a doença, a incapacidade, a miséria, o desemprego. Aqui, vale destacar que a Previdência brasileira surgiu apenas em 1923, com a Lei Elói Chaves, e bastante diferente da forma que hoje é concebida. Naquele tempo, era organizada por empresas e gerida pelas Caixas de Aposentadorias e Pensões (PAULUS JÚNIOR; CORDONI JÚNIOR, 2006).

Atualmente, cabe ao INSS, uma autarquia federal, vinculada ao Ministério da Previdência Social, promover a arrecadação, gerir os recursos, conceder e manter os benefícios previdenciários. A Assistência é prestada para quem dela necessitar, ou seja, independe de custeio e visa a fornecer um amparo para pessoas vivendo em extrema pobreza. Por meio do benefício assistencial de prestação continuada (BAPC), o Estado concede um salário mínimo ao idoso com mais de 65 anos ou à pessoa com deficiência, cuja renda per capita do grupo familiar seja inferior a $1 / 4$ (um quarto) do salário mínimo. 
Por fim, a saúde, objeto do presente artigo, constitui dever do Estado e direito de todo cidadão (art. 196, da Constituição). Independentemente de contribuição, ou seja, todo indivíduo tem o direito de ser atendido na rede pública de saúde.

O artigo 196 prevê a sua materialização mediante políticas sociais e econômicas voltadas à redução do risco de doença, além de garantir o acesso universal, gratuito e igualitário. ${ }^{3}$ A saúde possui autonomia no âmbito da Seguridade Social, é organizada de forma própria e seu escopo é o mais amplo dos ramos protetivos, haja vista não possuir qualquer restrição à clientela protegida (IBRAHIM, 2011). Se é assim, "[...] a saúde é garantida mediante políticas sociais e econômicas, visando à redução do risco de doença e de outros agravos, com o acesso universal e igualitário às ações e aos serviços necessários para sua promoção, proteção e recuperação." (IBRAHIM, 2011, p. 8).

Fixados esses conceitos, passa-se à análise da definição de políticas públicas de saúde, centrando-se no SUS.

\section{POLÍTICAS PÚBLICAS DE SAÚDE - O SUS}

Por meio do SUS, todo cidadão possui acesso à saúde, independentemente das necessidades sociais, da sua capacidade de pagar para o sistema, da sua condição no mercado de trabalho (se ativo ou desempregado), ou, ainda, de seu estado de saúde.

Bucci comenta que o SUS é resultado de um aprimoramento das técnicas e modelos anteriores à Constituição de 1988, mobilizando a esfera política e social "com vistas a alcançar o nível máximo de garantia proporcionado pelo sistema jurídico." (BUCCI, 2006, p. 17).

Dentre as influências, está o movimento de reforma sanitária, nos anos 70, responsável por fomentar o debate sobre a possibilidade de implementar um sistema de saúde público e de qualidade (CRUZ; TEIXEIRA; AZEVEDO, 2016).

Em resumo, o texto constitucional incorporou a ideia de que a saúde é "[...] produto das relações sociais e econômicas de determinada sociedade, por meio da indicação de que as políticas sociais e econômicas devem concorrer para a redução do risco de doença e de outros agravos." (DORES, 2013, p. 79). Antes disso, a saúde era tutelada como um direito exclusivo do cidadão pertencente a uma determinada classe ou categoria de trabalhadores. Em outros termos, era restrito aos indivíduos que exerciam atividade laborativa, por meio das caixas de assistência (MOURA; ORDACGY, 2014).

O próprio Ministério da Saúde somente foi criado em 1930, e, nesse início, o objetivo do Estado era fornecer o início da assistência médica individual (PAULUS JÚNIOR; CORDONI JÚNIOR, 2006). O caráter coletivo, com campanhas de vigilância sanitária, somente foi implementado em solo pátrio na década de 50, momento em que se nota o amparo médico no âmbito de instituições previdenciárias (PAULUS JÚNIOR; CORDONI JÚNIOR, 2006). 
Nos anos 70, os movimentos sociais e políticos contra a ditadura foram determinantes para o surgimento do SUS, conforme ensina Nelson Rodrigues dos Santos (SANTOS, 2013).

A reforma sanitária constituía uma bandeira para os anseios de uma sociedade mais justa e solidária, que buscava um Estado que pudesse proporcionar direitos humanos básicos.

A previsão constitucional foi regulamentada pela Lei 8.080/90. Logo, em seu artigo $2^{\mathrm{o}}{ }^{4}$ a Lei Orgânica do Sistema de Saúde Nacional reforça a premissa acerca da jusfundamentalidade da saúde, cabendo ao SUS a formulação e a execução de políticas públicas, voltadas não só ao cidadão, mas também ao profissional que nele atua, a fim de que exerça seu ofício com dignidade, em um ambiente salubre, além da iniciativa privada "[...] resguardando a saúde da população no exercício da atividade econômica e científica." (MOURA; ORDACGY, 2014, p. 55).

Importante destacar que o posicionamento é corroborado pela jurisprudência do Supremo Tribunal Federal (STF): "o direito à saúde é prerrogativa constitucional indisponível, garantido mediante a implementação de políticas públicas, impondo ao Estado a obrigação de criar condições objetivas que possibilitem o efetivo acesso a tal serviço." (BRASIL, 2010, online).

Nessa esteira, fala-se na aplicação imediata das normas definidoras dos direitos e das garantias fundamentais, não bastando a mera promessa, mas sim a concretização, porque a "constitucionalização de direitos implica na sua eficácia." (ZAGURSKI; PAMPLONA, 2016, p. 101).

Para atingir esse desiderato, o Estado vale-se das políticas públicas.

Ocorre que o conceito de política pública não é uníssono e, de acordo com Celina Souza, inexiste uma única ou melhor forma de conceituá-la (SOUZA, 2006). Há definições mais gerais, centradas em ações do governo, conduzindo o raciocínio de que seriam o conjunto de ações governamentais responsável por produzir determinados efeitos ou, então, a soma das atividades do governo que influenciam a vida dos indivíduos. Há quem se paute no critério finalístico, a solução dos problemas, valorizando aspectos racionais e procedimentais (SOUZA, 2006).

Nesse contexto, é importante olhar para o locus em que essas ideias se desenvolvem: nos governos. E, para essa tarefa, é imprescindível assumir uma visão holística do tema, não desprezando a fundamentalidade dos indivíduos, das instituições, das interações, dos interesses e das ideologias (SOUZA, 2006), eis que há repercussões políticas, econômicas e sociais. Ademais, por meio das políticas públicas, os governos "traduzem seus propósitos e plataformas eleitorais em programas e ações que produzirão resultados ou mudanças no mundo real." (SOUZA, 2006, p. 26).

A ação estratégica é, de acordo com Maria Paula Dallari Bucci, um traço distintivo das políticas públicas, pois "incorpora elementos sobre a ação necessária e possível naquele momento determinado, naquele conjunto institucional e projeta-os para o futuro mais próximo." (BUCCI, 2006, p. 19). Esses elementos podem decorrer de uma exigência popular, de um fato, de uma pesquisa, até mesmo pelo anseio de reeleição ou por interesses políticos (MESQUITA; PAMPLONA, 2015). 
De qualquer maneira, cabendo à Administração pôr em prática as diretrizes estabelecidas no texto constitucional, promovendo direitos fundamentais, tal mecanismo necessita de ações e programas, dos mais variados tipos.

Nessa esteira, "é fácil perceber que apenas por meio das políticas públicas o Estado poderá, de forma sistemática e abrangente, realizar os fins previstos na Constituição (e, muitas vezes, detalhados pelo legislador) [...]" (BARCELLOS, 2008, p. 116-117), especialmente no que tange aos direitos fundamentais cuja fruição depende de ações. $\mathrm{O}$ conceito clássico de políticas públicas é de Maria Paula Dallari Bucci:

Política pública é definida como programa ou quadro de ação governamental, porque consiste num conjunto de medidas articuladas (coordenadas), cujo escopo é dar impulso, isto é, movimentar a máquina do governo, no sentido de realizar algum objetivo de ordem pública ou, na ótica dos juristas, concretizar um direito (BUCCI, 2006, p. 14).

No que tange às políticas públicas de saúde, estas "[...] devem garantir o acesso ao serviço público hospitalar e ambulatorial para todos os cidadãos independentemente de condições pessoais, sem preconceitos ou privilégios" (MOURA; ORDACGY, 2014, p. 57), observando a continuidade das prestações oferecidas pelo Estado e a eficiência de técnicas e processos para garantir o melhor desempenho possível.

Nesse contexto, vale lembrar que a promoção da saúde impulsiona a qualidade de vida, reduz a vulnerabilidade social e promove o desenvolvimento sustentável (SANTOS et al., 2016).

Essa proteção decorre de valores incorporados pelo constitucionalismo contemporâneo, não sendo diferente o brasileiro, fazendo que as disposições constantes na Constituição sejam dotadas de normatividade, ou seja, produzem efeitos e "desfrutam da imperatividade própria do direito". Além disso, "gozam de superioridade hierárquica no âmbito do sistema jurídico.” (BARCELLOS, 2008, p. 115).

Outro axioma teórico do constitucionalismo contemporâneo, conforme ensinamento de Barcellos, é o status diferenciado dos direitos fundamentais. Eles configuram o centro do ordenamento jurídico pátrio, significando que "[...] tanto o Estado como o Direito existem para proteger e promover os direitos fundamentais, de modo que tais estruturas devem ser compreendidas e interpretadas em conta dessa diretriz." (BARCELLOS, 2008, p. 115). Por fim, não se pode olvidar que os poderes são submissos à Constituição, responsável por estabelecer vinculações aos agentes políticos, especialmente no que se refere à promoção dos direitos fundamentais (BARCELLOS, 2008).

Ocorre que é corriqueira a informação acerca da insuficiência do Estado em prover os direitos constitucionalmente consagrados, especialmente na área da saúde. Até porque "[...] o fato é que toda e qualquer ação estatal envolve gasto de dinheiro público, e os recursos públicos são limitados." (BARCELLOS, 2008, p. 117).

Necessário, portanto, avaliar como ocorre o financiamento da saúde. 


\section{AS LIMITAÇÕES ORÇAMENTÁRIAS E O FINANCIAMENTO DA SAÚDE}

A saúde, como um direito social, está vinculada à segunda dimensão dos direitos fundamentais, também são denominados como sendo prestacionais. Bucci os considera como direitos-meio, haja vista destinarem-se a assegurar o indivíduo a gozar dos direitos individuais de primeira dimensão (BUCCI, 2006).

Isso não implica dizer que a saúde possui caráter absoluto, pois, conforme entendimento do STF,

Não há, no sistema constitucional brasileiro, direitos ou garantias que se revistam de caráter absoluto, mesmo porque razões de relevante interesse público ou exigências derivadas do princípio de convivência das liberdades legitimam, ainda que excepcionalmente, a adoção, por parte dos órgãos estatais, de medidas restritivas das prerrogativas individuais ou coletivas, desde que respeitados os termos estabelecidos pela própria Constituição. O estatuto constitucional das liberdades públicas, ao delinear o regime jurídico a que estas estão sujeitas - e considerado o substrato ético que as informa - permite que sobre elas incidam limitações de ordem jurídica, destinadas, de um lado, a proteger a integridade do interesse social e, de outro, a assegurar a coexistência harmoniosa das liberdades, pois nenhum direito ou garantia pode ser exercido em detrimento da ordem pública ou com desrespeito aos direitos e garantias de terceiros (BRASIL, 1999, online).

O trecho acima demonstra que a Suprema Corte brasileira se posiciona no sentido de haver limitações aos direitos fundamentais. Assim, é possível afirmar que "os serviços públicos, enquanto atividades prestadas pelo Estado em função da fruição dos interesses da coletividade, submetem-se a princípios gerais que impõem ao administrador o dever de garantir a sua generalidade, a sua continuidade e a sua eficiência.” (MOURA; OSDACGY, 2014, p. 50).

Uma dessas restrições seria de índole orçamentária, pois o planejamento estatal é materializado por meio do orçamento

[...] que estabelece um conjunto de ações a serem realizadas, durante um período de tempo determinado, estimando o montante das fontes de recursos a serem arrecadados pelos órgãos e entidades públicas e fixando o montante de recursos a serem aplicados pelos mesmos na consecução dos seus programas de trabalho, a fim de manter ou ampliar os serviços públicos, bem como realizar obras que atendam as necessidades da população (MOTA, 2009, p. 26).

De outro giro, o texto constitucional impõe um mínimo a ser aplicado em ações e serviços públicos de saúde. ${ }^{5}$ Os mínimos a serem investidos e o cumprimento dos dispositivos constitucionais são expressos por meio de leis orçamentárias, como o Plano Plurianual (PPA) que é um "instrumento de planejamento definidor de objetivos, diretrizes e metas da Administração Pública Federal para o período de quatro anos, que compreende todos os recursos do Estado, organizando o gasto de maneira a gerar os melhores resultados possíveis" (PEREIRA, 2015, p. 294), a Lei de Diretrizes Orçamentárias (LDO), que, dentro do PPA, lista quais os programas de prioridade na execução do orçamento e a Lei Orçamentária Anual (LOA), responsável por vincular os recursos à execução das políticas públicas. 
Nesse contexto, importante destacar o advento da Emenda Constitucional n ${ }^{\circ}$ 95/2016, que alterou o ato das disposições constitucionais transitórias, instituiu novo regime fiscal e estabeleceu um teto para despesas primárias. Em resumo, o ato desvinculou "[...] das despesas com saúde e educação na CF com relação às receitas, e seu congelamento no valor real de 2016" (VIEIRA; BENEVIDES, 2016, p. 7). Dessa forma, o congelamento do gasto por 20 anos, com valores de 2016, afetará negativamente os serviços de saúde. Tal premissa decorre do fato de que a população brasileira aumentará e envelhecerá, aumentando a demanda e os custos do SUS.

Tecidas essas considerações e partindo do fato de que o Estado não dispõe de recursos próprios para fornecer os direitos e as garantias preconizados pela Constituição, a sociedade é chamada para contribuir com o financiamento (FAIM FILHO, 2011). Nos Estados contemporâneos, esses recursos advêm, essencialmente, dos tributos. Marcelo Guerra Martins lembra que "todas as obrigações que envolvem o Estado (seja como credor ou devedor) são satisfeitas por meio do dinheiro (v.g. pagamento de tributos, remuneração dos funcionários públicos, contratação de compras e serviços diversos etc)" (MARTINS, 2011, p. 822). Assim, não há como fugir à regra de que "as ações estatais capazes de realizar os direitos fundamentais pressupõem decisões acerca do dispêndio de recursos públicos." (BARCELLOS, 2008, p. 116).

Conforme visto anteriormente, a Constituição ampliou os direitos sociais em nosso país, sendo natural, portanto, que o Brasil passasse a adotar medidas visando a garantir a aplicação dos recursos em áreas determinadas.

Trata-se de mecanismo voltado a impedir ou, ao menos, dificultar, o corrompimento das finalidades.

Nessa esteira, no artigo 195, cuidou o constituinte de tratar da forma de financiamento de modelo de Seguridade Social, estabelecendo que esta será custeada de duas formas: diretamente, pelas contribuições sociais e indiretamente, mediante recursos provenientes dos orçamentos da União, dos Estados, do Distrito Federal e dos Municípios.

Analisando esse dispositivo, pode-se afirmar que a Constituição demonstrou acentuada preocupação em criar uma fonte de financiamento capaz de atender aos serviços oferecidos pela Seguridade Social, impondo a responsabilidade pelo custeio a toda população. As contribuições sociais podem ser definidas como uma espécie tributária, em que pese haver controvérsia na doutrina. ${ }^{6}$ Para o presente trabalho, importante ressaltar que o traço diferenciador desse tributo é a destinação, ou seja, indispensável se torna o exame do momento posterior ao da arrecadação.

Diferem-se, nesse quesito, dos impostos, os quais são carreados a uma caixa comum e, portanto, financiam despesas gerais, garantindo a flexibilidade na gestão administrativa, eis que os recursos podem ser realocados para uma área específica, em dificuldade orçamentária (MARTINS, 2011).

Para sua cobrança, os impostos independem de uma atuação estatal específica, como dispõe o artigo 16 do Código Tributário Nacional (CTN). ${ }^{7}$ Consequentemente, fala-se na ausência de vinculação dos impostos, e o seu corrompimento não é considerado 
inconstitucional, mesmo que afete a aplicação de parte de recursos a áreas como saúde e educação (MARTINS, 2011).

O mesmo raciocínio, contudo, não se aplica às contribuições em geral, que foram implementadas pelo constituinte justamente para atender a finalidades específicas, sendo este seu traço diferencial, conforme explicam Santi e Canado (2009).

Em outros termos, ao depararmos com as contribuições, não basta examinar o momento de recebimento do tributo, é indispensável o controle do momento posterior: "o momento da destinação do quantum pago pelo contribuinte." (SANTI; CANADO, 2009, p. 621). Se não for possível controlar a destinação das contribuições, haverá a sua desqualificação, comprometendo até mesmo a sua existência (SANTI; CANADO, 2009), especialmente quando se fala das contribuições, eis que têm "finalidade específica e referibilidade." (MACHADO, 2011, p. 1050).

E a doutrina pátria é forte nesse sentido. ${ }^{8}$ Martins fala que se trata de uma questão de causa e efeito: a desvinculação das contribuições padece de constitucionalidade (MARTINS, 2011). Não por acaso, portanto, que há tempos Fernando Facury Scaff alerta para a importância do estudo da segunda e da terceira dimensão de direitos quando abordado o debate inerente aos direitos humanos e tributação (SCAFF, 2004). A vinculação das receitas a determinadas despesas pode ser um empecilho para alguns administradores públicos. Nesse sentido, João Batista Lazzari comenta que a maior dificuldade para implantação do SUS foi a existência de um "financiamento definido e suficiente para os investimentos na rede de serviços, à cobertura assistencial ambulatorial e hospitalar e às demais ações de saúde." (LAZZARI, 2003, p. 76). Para os fins do presente artigo, não se irá examinar a inconstitucionalidade da ausência de destinação, mas sim o impacto dessa medida nas políticas públicas de saúde.

\section{A DESVINCULAÇÃO DE RECEITAS DA UNIÃO}

A DRU é um mecanismo criado em 1994 que desobriga a União a repassar recursos vinculados à Seguridade Social e às contribuições sociais. É considerada uma regra sui generis e polêmica pelo fato de atribuir finalidade diversa à parcela do arrecadado pela União (MARTINS, 2011).

O objetivo do governo, naquela época de transição da moeda e da estabilidade econômica gerada pelo Plano Real, era possuir um instrumento temporário de desvinculação, "pois havia o temor de que, sem a corrosão no valor real das despesas orçamentárias provocada pela elevada inflação, os orçamentos da União ficassem excessivamente engessados.” (COSTA; TOLLINI, 2011, p. 945).

Sua instituição ocorreu por meio da Emenda Constitucional de Revisão (ECR) n. 1/94 e, na ocasião, foi denominada Fundo Social de Emergência (FSE). A vigência desse fundo durou 2 anos, sendo renovado em 1996, pela EC 10/96, que passou a denominá-lo de Fundo 
de Estabilização Fiscal (FEF). Tratava-se do início da estratégia governamental "de liberar parte das receitas vinculadas para supostamente promover o ajuste fiscal." (MARTINS, 2011, p. 833). Uma nova renovação ocorreu em 1997, por meio da EC 17/97, até que, em 2000, nasceu a DRU, cujos efeitos "estão restritos às desvinculações das contribuições sociais e das contribuições econômicas. A educação deixou de perder recursos com a EC n. 59/2009." (ASSOCIAÇÃO NACIONAL DOS AUDITORES-FISCAIS DA RECEITA FEDERAL DO BRASIL, 2015, p. 136).

A DRU, portanto, estava programada inicialmente para viger somente até dezembro de 2003, contudo vem sendo renovada e permanece ativa (MARTINS, 2011). Com isso, parte da receita arrecadada pela Seguridade Social tem sido corrompida pela desvinculação de receitas da União. A sua previsão é no artigo 76 do ADCT, que retirava, até o ano de 2015, 20\% da arrecadação da União relativa às contribuições sociais, de intervenção no domínio econômico e taxas. Portanto, qualquer análise da importância que os direitos sociais tenham no Brasil deve ser feita a partir dos recursos que lhe são efetivamente destinados. Somente observar os dispositivos constitucionais que garantem a atribuição de recursos para a saúde, por exemplo, não é o suficiente para uma conclusão acurada sobre o tema. Necessário é, ainda, levar-se em consideração o percentual permitido de desvinculação. $\mathrm{O}$ sistema funciona de modo a, por uma via, destinar recursos, e, por outra via, retirá-los do montante da destinação.

Em 2016, a DRU foi renovada e majorada para 30\%:

Art. 76. São desvinculados de órgão, fundo ou despesa, até 31 de dezembro de 2023, 30\% (trinta por cento) da arrecadação da União relativa às contribuições sociais, sem prejuízo do pagamento das despesas do Regime Geral da Previdência Social, às contribuições de intervenção no domínio econômico e às taxas, já instituídas ou que vierem a ser criadas até a referida data (BRASIL, 2016, online).

Essas sucessivas prorrogações afetam diretamente o equilíbrio financeiro e atuarial da Seguridade Social, do qual faz parte a Saúde, pois praticamente um terço das contribuições sociais são aplicadas em áreas estranhas à Seguridade Social.

Anualmente a Associação Nacional dos Auditores-Fiscais da Receita Federal do Brasil (ANFIP) divulga um estudo denominado Análise da Seguridade Social, no qual faz um balanço das receitas e das despesas desse sistema protetivo, a fim de verificar a sua viabilidade e sustentabilidade. Essa obra é de fundamental importância para desmistificar certos conceitos usualmente divulgados acerca do déficit da Seguridade Social.

O relatório divulgado no ano de 2015 refere-se à execução do orçamento da Seguridade Social em 2014, considerando, ainda, números de anos anteriores. Vale destacar que o país experimentou, desde 2014, um aumento do desemprego, da retenção econômica e um aumento das renúncias tributárias (ASSOCIAÇÃO NACIONAL DOS AUDITORES-FISCAIS DA RECEITA FEDERAL DO BRASIL, 2015).

Em que pese esse baixo crescimento econômico e volumosas desonerações, a ANFIP informa que a Seguridade Social apresentou bons números em 2014, com receitas superiores às despesas, ou seja, o sistema foi superavitário. A arrecadação foi de $\mathrm{R} \$ 686,1$ bilhões, 
superando em $\mathrm{R} \$ 35,1$ bilhões a arrecadação de 2013 (ASSOCIAÇÃO NACIONAL DOS AUDITORES-FISCAIS DA RECEITA FEDERAL DO BRASIL, 2015).

Já as despesas da Seguridade somaram R\$632,2 bilhões, 10\% acima dos valores de 2013. De qualquer forma, o Orçamento da Seguridade Social apresentou um resultado positivo, em 2014, de R \$53,9 bilhões (ASSOCIAÇÃO NACIONAL DOS AUDITORES-FISCAIS DA RECEITA FEDERAL DO BRASIL, 2015).

Somente por esses números, verifica-se que, apesar de superavitário, os gastos da Seguridade Social vêm se acentuando. E, de acordo com a ANFIP, a principal fonte de esvaziamento decorre da Desvinculação de Receitas da União (DRU).

Em 2014, a DRU retirou do Orçamento da Seguridade Social R\$ 63,2 bilhões, ou seja, $10 \%$ das despesas contabilizadas no ano anterior. Assim, na contramão das necessidades da população, a DRU demanda uma redução nas despesas por retirar do orçamento a previsão de valores constitucionalmente recolhidos para cobrir exatamente a Seguridade Social. Trata-se de quantia significativa que compromete a viabilidade do sistema a longo prazo e, especialmente, a implementação de novos benefícios à população (ASSOCIAÇÃO NACIONAL DOS AUDITORES-FISCAIS DA RECEITA FEDERAL DO BRASIL, 2015). Em 2013, a retirada foi de $\mathrm{R} \$ 63,4$ bilhões, de acordo com a ANFIP (ASSOCIAÇÃO NACIONAL DOS AUDITORES-FISCAIS DA RECEITA FEDERAL DO BRASIL, 2014).

E o mais impactante é que "essa subtração de recursos não aparece nos relatórios governamentais como uma transferência de recursos da Seguridade Social para o Orçamento Fiscal. É como se esses recursos fossem, por natureza, do Orçamento Fiscal." (ASSOCIAÇÃO NACIONAL DOS AUDITORES-FISCAIS DA RECEITA FEDERAL DO BRASIL, 2015, p. 137).

Franselmo Araújo Costa e Helio Martins Tollini, em artigo que aborda as vinculações das receitas orçamentárias fiscais e da Seguridade Social, expuseram que, no ano de 2011, o "déficit" foi de R $\$ 50$ bilhões de reais (COSTA; TOLLINI, 2011). Contudo, a DRU foi responsável por suprimir $\mathrm{R} \$ 51,8$ bilhões. Em outros termos, nota-se que o mecanismo corrompeu as contas da Seguridade Social. Caso não houvesse a DRU, não haveria que se falar em despesas superiores às receitas.

Durante o período de 1995 a 2005, a DRU desviou R 267 bilhões (GENTIL, 2006). E mais, considerando o período de 1999 a 2005, as receitas da Seguridade Social sempre foram superiores aos gastos, produzindo excedente para o orçamento fiscal (GENTIL, 2006). De acordo com esses dados, observa-se que a Seguridade Social como um todo e, portanto, a Saúde, a Previdência e a Assistência são afetadas com as desvinculações realizadas pela DRU.

Sem a aplicação desse mecanismo, mais recursos poderiam ser utilizados para aprimoramento do SUS e das políticas públicas de saúde como um todo, como na contratação de servidores, na modernização dos equipamentos, na construção de novos hospitais, na realização de campanhas preventivas, o que contribuiria, e muito, para garantir eficiência a esse direito fundamental. 


\title{
6 CONSIDERAÇÕES FINAIS
}

As finanças públicas são determinantes para os objetivos de um país, exercendo grande influência na possibilidade de desenvolvimento econômico e social. Assim, cresce a importância da gestão pública, especialmente no que se refere ao dinheiro arrecadado.

Nesse contexto, por ser o Brasil uma república federativa e democrática, os gastos governamentais devem corresponder aos anseios do povo. Raquel Cavalcanti Ramos Machado ensina que a receita pública, em um Estado Social e Democrático de Direito, não se limita a legitimar o diálogo do Estado e da sociedade, vai além: deve possibilitar a concretização de direitos sociais, respeitando a capacidade contributiva e a possibilidade de desenvolvimento individual (MACHADO, 2011).

Essa perspectiva é de suma importância para as políticas públicas, não sendo diferente com as de saúde. A Constituição de 1988 impõe que esse direito deve ser garantido mediante políticas sociais e econômicas, as quais, conforme visto nesse artigo, dependem do orçamento de cada ente da federação. Nesse contexto, a implementação desse direito fundamental depende de recursos.

No que tange à estrutura tributária da União, quando se fala das contribuições, é inegável a necessidade da destinação. Assim, com a Desvinculação de Receitas da União (DRU), não pode o Estado alegar escassez de recursos, a fim de justificar a precariedade do Sistema Único de Saúde (SUS) ou, então, para promover reformas previdenciárias.

A concepção de constitucionalismo contemporâneo faz com que os direitos garantidos constitucionalmente devam ser concretizados, sendo papel do Estado aplicar adequadamente os recursos arrecadados e, dessa forma, atender às necessidades coletivas.

Não é o que vem ocorrendo com o sistema de Seguridade Social brasileiro, cujo orçamento é afetado pela DRU, impactando a realização de políticas públicas.

Nesse contexto, é imperiosa a participação mais ativa da sociedade na elaboração e aprovação de orçamentos, de audiências públicas, de execução dos atos governamentais, de modo a ter políticas públicas adequadas à realidade e às necessidades coletivas.

Igualmente se revela importante a fiscalização do orçamento por meio das entidades representativas, pelos órgãos de classe, pelos auditores da receita federal para aumentar o controle e a transparência sobre o emprego e os gastos públicos.

\section{THE IMPACT OF DETACHING UNION REVENUE ON PUBLIC HEALTH POLICIES}

\begin{abstract}
The 1988 Constitution implemented the model of Social Security in Brazil, formed by Social Security, Assistance and Health. These are social rights, of the second dimension, which require actions by the State apparatus. For the purposes of this article, the methodological
\end{abstract}


cut is made in Health and, especially, in the form proposed to make it effective: through public policies. To achieve this, it is indispensable to have resources. And the Social Security budget is directly affected by an institute called Detachment of Union Revenue, which is responsible for assigning a different purpose to the amount collected as social contributions. Thus, the premise of the lack of financial resources for the State to provide due protection to the individual in this area remains controversial, and the purpose of this article is to deepen the knowledge of the subject. In order to reach this goal, the work initially addressed the Brazilian Social Security, focusing on the Universal Health System (Sistema Único de Saúde), to then examine the public health policies, their financing and, finally, the Detachment of Union Revenue.

Keywords: Social Security. Detachment of Union Revenue. Public Policy. Health.

\section{EL IMPACTO DE LA DESVINCULACIÓN DE HACIENDAS DE LA UNIÓN EN POLÍTICAS PÚBLICAS DE SALUD}

\section{RESUMEN}

La Constitución de 1988 implementó el modelo de Seguridad Social en el país, compuesto por la Previdencia, la Asistencia y la Salud. Se tratan de derechos sociales, de segunda dimensión, que necesitan de acciones del Estado. Para los fines del presente artículo, el recorte metodológico es realizado en la Salud, y, en especial, en la forma con que el ordenamiento establecido propuso para tornarla efectiva: a través de políticas públicas. Para atingir ese fin, es indispensable la existencia de recursos. Y el presupuesto de la Seguridad Social es afectado directamente por un instrumento denominado Desvinculación de Haciendas de la Unión (DRU), responsable por atribuir finalidad diversa al montante arrecadado como contribuciones sociales. Así, queda controvertida la premisa de ausencia de recursos financieros para que el Estado fornezca la debida protección al individuo en ese tema; el objetivo de este artículo es de profundizar el conocimiento en el asunto. Para atingir esa aspiración, el trabajo abordó inicialmente la seguridad social brasileña, con enfoque en el SUS, para entonces examinar las políticas públicas de salud, su financiamiento y, por fin, la DRU.

Palabras-clave: Seguridad Social. Desvinculación de Haciendas de la Unión. Políticas Públicas. Salud.

1 Art. $6^{\circ}$. São direitos sociais a educação, a saúde, a alimentação, o trabalho, a moradia, o transporte, o lazer, a segurança, a previdência social, a proteção à maternidade e à infância, a assistência aos desamparados, na forma desta Constituição.

2 Art. 194. A seguridade social compreende um conjunto integrado de ações de iniciativa dos Poderes Públicos e da sociedade, destinadas a assegurar os direitos relativos à saúde, à previdência e à assistência social.

Parágrafo único. Compete ao Poder Público, nos termos da lei, organizar a seguridade social, com base nos seguintes objetivos: 
I - universalidade da cobertura e do atendimento;

II - uniformidade e equivalência dos benefícios e serviços às populações urbanas e rurais;

III - seletividade e distributividade na prestação dos benefícios e serviços;

IV - irredutibilidade do valor dos benefícios;

$\mathrm{V}$ - equidade na forma de participação no custeio;

VI - diversidade da base de financiamento;

VII - caráter democrático e descentralizado da administração, mediante gestão quadripartite, com participação dos trabalhadores, dos empregadores, dos aposentados e do Governo nos órgãos colegiados.

3 Art. 196. A saúde é direito de todos e dever do Estado, garantido mediante políticas sociais e econômicas que visem à redução do risco de doença e de outros agravos e ao acesso universal e igualitário às ações e serviços para sua promoção, proteção e recuperação.

4 Art. $2^{\circ}$. A saúde é um direito fundamental do ser humano, devendo o Estado prover as condições indispensáveis ao seu pleno exercício.

$\S 1^{\circ} \mathrm{O}$ dever do Estado de garantir a saúde consiste na formulação e execução de políticas econômicas e sociais que visem à redução de riscos de doenças e de outros agravos e no estabelecimento de condições que assegurem acesso universal e igualitário às ações e aos serviços para a sua promoção, proteção e recuperação.

$\S 2^{\circ} \mathrm{O}$ dever do Estado não exclui o das pessoas, da família, das empresas e da sociedade.

5 Art. 198. As ações e serviços públicos de saúde integram uma rede regionalizada e hierarquizada e constituem um sistema único, organizado de acordo com as seguintes diretrizes:

$[\ldots]$

$\S 2^{\circ}$ A União, os Estados, o Distrito Federal e os Municípios aplicarão, anualmente, em ações e serviços públicos de saúde recursos mínimos derivados da aplicação de percentuais calculados sobre: (Incluído pela Emenda Constitucional $n^{\circ} 29$, de 2000)

I - no caso da União, a receita corrente líquida do respectivo exercício financeiro, não podendo ser inferior a 15\% (quinze por cento); (Redação dada pela Emenda Constitucional no 86, de 2015)

II - no caso dos Estados e do Distrito Federal, o produto da arrecadação dos impostos a que se refere o art. 155 e dos recursos de que tratam os arts. 157 e 159, inciso I, alínea a, e inciso II, deduzidas as parcelas que forem transferidas aos respectivos Municípios; (Incluído pela Emenda Constitucional n 29, de 2000)

III - no caso dos Municípios e do Distrito Federal, o produto da arrecadação dos impostos a que se refere o art. 156 e dos recursos de que tratam os arts. 158 e 159, inciso I, alínea b e $§ 3^{\circ}$. (Incluído pela Emenda Constitucional $n^{\circ} 29$, de 2000)

6 Para embasar a assertiva acerca da natureza jurídica das contribuições sociais, utilizou-se a doutrina de Paulsen e Velloso (2013, p. 61).

7 Art. 16. Imposto é o tributo cuja obrigação tem por fato gerador uma situação independente de qualquer atividade estatal específica, relativa ao contribuinte.

8 Dentre os exemplos citam-se: Greco (2000). Ataliba (1997).

\section{REFERÊNCIAS}

ASSOCIAÇÃO NACIONAL DOS AUDITORES-FISCAIS DA RECEITA FEDERAL DO BRASIL. Análise da Seguridade Social 2014. Brasília: ANFIP, 2015.

. Análise da Seguridade Social 2013. Brasília: ANFIP, 2014.

ATALIBA, Geraldo. Hipótese de incidência tributária. São Paulo: Malheiros, 1997.

BARCELLOS, Ana Paula de. Constitucionalização das políticas públicas em matéria de direitos fundamentais: o controle político-social e o controle jurídico no espaço democrático. In: SARLET, Ingo Wolfgang; TIMM, Luciano Benetti (Org.). Direitos fundamentais: orçamento e "reserva do possível". Porto Alegre: Livraria do Advogado, 2008. 
BRASIL. Supremo Tribunal Federal. Agravo Regimental no Agravo de Instrumento $\mathbf{n}^{\mathbf{o}}$ 734.487. Relator: Min. Ellen Gracie. Paraná, 3 de agosto de 2010. $2^{\text {a }}$ T, DJE de 20 de agosto de 2010. Disponível em: <http://redir.stf.jus.br/paginadorpub/paginadorjsp?docTP=AC\& docID $=613652>$. Acesso em: 13 set. 2016 .

. Supremo Tribunal Federal. Mandado de Segurança 23452, de 16 de setembro de 1999. Relator: Celso de Mello. Brasília, setembro de 1999. Disponível em: < http://www.stf. jus.br/portal/jurisprudencia/visualizarEmenta.asp?s $1=000020700 \&$ base $=$ baseAcordaos $>$. Acesso em: 13 set. 2016.

. Emenda constitucional n ${ }^{\circ}$ 93, de 8 de setembro de 2016. Altera o Ato das Disposições Constitucionais Transitórias para prorrogar a desvinculação de receitas da União e estabelecer a desvinculação de receitas dos Estados, Distrito Federal e Municípios. Presidência da República, Brasília, set. 2016. Disponível em: <http://www.planalto.gov.br/ccivil_03/ constituicao/emendas/emc/emc93.htm>. Acesso em: 13 set. 2016.

BUCCI, Maria Paula Dallari. O conceito de política pública em direito. In: BUCCI, Maria Paula Dallari (Org.). Políticas públicas: reflexões sobre o conceito jurídico. São Paulo: Saraiva, 2006.

COSTA, Franselmo Araújo; TOLLINI, Hélio Martins. Vinculações das receitas orçamentárias: teoria e prática. In: CONTI, José Maurício; SCAFF, Fernando Facury (Org.). Orçamentos públicos e direito financeiro. São Paulo: Revista dos Tribunais, 2011. v. 1. p. 933-956.

CRUZ, César Albenes de Mendonça; TEIXEIRA, Janine Vieira; AZEVEDO, Ana Paula. Universalidade do atendimento à saúde no Brasil: impasses e perspectivas. Revista de Políticas Públicas, Maranhão, v. 20, p. 201-220-220, 2016.

DIAS, Maria Socorro de Araújo et al. Judicialização da saúde pública brasileira. Revista Brasileira de Políticas Públicas, Brasília, v. 2, p. 133-146, 2016.

DORES, Camilla Japiassu. As bases da saúde lançadas pela Constituição Federal de 1988: um sistema de saúde para todos? Revista Brasileira de Políticas Públicas, Brasília, v. 3, p. 77-89, 2013. FAIM FILHO, Eurípedes Gomes. A Judicialização da Saúde e seus Reflexos Orçamentários. In: CONTI, José Mauricio; SCAFF, Fernando Facury (Org.). Orçamentos públicos e direto financeiro. São Paulo: Revista dos Tribunais, 2011. v. 1. p. 1009-1044.

GENTIL, Denise Lobato. A política fiscal e a falsa crise da seguridade social brasileira: análise financeira do período 1990-2005. 2006. 128 f. Tese (Doutorado) - Instituto de econômica, do centro de ciências jurídicas e econômicas da Universidade Federal do Rio de Janeiro, Rio de Janeiro, 2006.

GRECO, Marco Aurélio. Contribuições: uma figura sui generis. São Paulo: Dialética, 2000. HALL, Peter A.; LAMONT, Michéle. Introduction. In: HALL, Peter A.; LAMONT, Michéle (Org.). Successful societies: how institutions and culture affect health. New York: Cambridge University Press, 2009. E-book. 
HALL, Peter A; TAYLOR, Rosemary CR. Health, social relations and public policy. In: HALL, Peter A.; LAMONT, Michéle (Org.). Successful societies: how institutions and culture affect health. New York: Cambridge University Press, 2009. E-book.

IBRAHIM, Fábio Zambitte. Curso de direito previdenciário. Rio de Janeiro: Impetus, 2011. LAZZARI, João Batista. Fontes de Financiamento do Sistema Único de Saúde. Revista de Direito Sanitário, São Paulo, v. 4, p. 75-84, 2003.

MACHADO, Raquel Cavalcanti Ramos. A mudança do paradigma orçamentário: do controle do estado para a implementação de políticas públicas: a função da receita pública no Estado Democrático e Social de Direito. In: CONTI, José Mauricio; SCAFF, Fernando Facury. (Org.). Orçamentos públicos e direto financeiro. São Paulo: Revista dos Tribunais, 2011.v. 1. p. 1045-1066.

MARTINS, Marcelo Guerra. As vinculações das receitas públicas no orçamento. In: CONTI, José Maurício; SCAFF, Fernando Facury (Org.). Orçamentos públicos e direito financeiro. São Paulo: Revista dos Tribunais, 2011.v. 1. p. 821-845.

MESQUITA, Eduardo Melo de; PAMPLONA, Danielle Anne Pamplona. Judiciário e políticas públicas: um exemplo positivo. Novos Estudos Jurídicos, Santa Catarina, v. 20, n. 3, p. 885-906, 2015.

MOTA, Francisco Glauber Lima. Contabilidade aplicada ao setor público. Brasília: Coleção Gestão Pública, 2009.

MOURA, Emerson Affonso da Costa; ORDACGY, Fabrizia da Fonseca Passos Bittencourt. Direito à saúde, políticas públicas do Sistema Único de Saúde e o acesso ao serviço público hospitalar e ambulatorial. Revista Brasileira de Políticas Públicas, Brasília, v. 4, p. 49-59, 2014.

PAULSEN, Leandro; VELLOSO, Andrei Pitten. Contribuições: teoria geral, contribuições em espécie. Porto Alegre: Livraria do Advogado Editora, 2013.

PAULUS JÚNIOR, Aylton; CORDONI JÚNIOR, Luiz. Políticas públicas de saúde no Brasil. Espaço para a Saúde, Paraná, v. 8, p. 13-19, 2006.

PEREIRA, Fernanda Tercetti Nunes. Ativismo Judicial e Direito à Saúde: a judicialização das políticas públicas de saúde e os impactos da postura ativista do Poder Judiciário. Revista Brasileira de Políticas Públicas, Brasília, v. 5, p. 291-308, 2015.

SANTI, Eurico Marcos Diniz de; CANADO, Vanessa Rahal. Direito Tributário e direito financeiro? Reconstruindo o conceito de tributo e resgatando o controle da destinação. In: SANTI, Eurico Marcos Diniz de. Curso de direito tributário e finanças públicas: do fato à norma, da realidade ao conceito jurídico. São Paulo: Saraiva, 2009.

SANTOS, Débora Aparecida Silva et al. Percorrendo os caminhos da relação entre as políticas públicas de saúde e do meio ambiente. Revista de Políticas Públicas, Maranhão, v. 20, p. 137-152, 2016. 
SANTOS, Nelson Rodrigues dos. SUS, política pública de Estado: seu desenvolvimento instituído e instituinte e a busca de saídas. Ciência de saúde coletiva, Rio de Janeiro, v. 18, n. 1, p. 273-280, jan. 2013.

SANTOS, Nelson Rodrigues. Políticas públicas de saúde: qual o rumo?. Cebes Centro Brasileiro de Estudos de Saúde, Rio de Janeiro, 2013. Disponível em: <http://cebes.org. br/site/wp-content/uploads/2013/10/Sus_politica.pdf>. Acesso em: 13 set. 2016.

SAVARIS, José Antonio. Direito processual previdenciário. Curitiba: Alteridade Editora, 2016.

SCAFF, Fernando Facury. Direitos humanos e a desvinculação das Receitas da União. Revista de Direito Administrativo, Rio de Janeiro, v. 236, p. 33-50, 2004.

SOUZA, Celina. Políticas públicas: uma revisão da literatura. Sociologia, Porto Alegre, v. 8, n. 16, p. 20-45, 2006.

TORRES, Ricardo Lobo. Tratado de direito constitucional financeiro e tributário: o orçamento na constituição. Rio de Janeiro: Renovar, 2005. v. 5.

VIEIRA, Fabiola Sulpino; BENEVIDES, Rodrigo Pucci de Sá e. Nota Técnica Ipea no 28: os impactos do novo regime fiscal para o financiamento do Sistema Único de Saúde e para a efetivação do direito à saúde no Brasil. Brasília: IPEA, 2016. (Nota técnica).

ZAGURSKI, Adriana Timóteo; PAMPLONA, Danielle Anne. Judicialização da saúde e orçamento público. Revista do Direito, Rio Grande do Sul, v. 1, p. 92-117, 2016.

Submetido: 9 jun. 2017

Aprovado: 18 set. 2017 